\title{
The effect of an unsaturated-fat diet on cataract formation in streptozotocin-induced diabetic rats
}

\author{
By J. C. HUTTON, P. J. SCHOFIELD, J. F. WILLIAMS, H. L. REGTOP \\ AND F. C. HOLLOWS* \\ School of Biochemistry, University of New South Wales, \\ Kensington, NSW 2033, Australia \\ (Received $7 \mathfrak{F u l y}$ I975 - Accepted 30 October 1975)
}

\begin{abstract}
1. Cataract formation in streptozotocin-induced diabetes in rats was reduced by approximately $85 \%$ when a diet rich in maize oil $(300 \mathrm{~g} / \mathrm{kg} \mathrm{diet})$ (fat diet) was given, thus confirming results of earlier studies. However, the concentration of sorbitol in the lens of diabetic animals remained high, the values for diabetic rats given the standard diet and the fat diet being 65 and $40 \mu \mathrm{mol} / \mathrm{g}$ protein respectively.

2. With the standard diet, the fatty acid profile of the triglycerides of the epididymal fat pads was characterized by a greater relative proportion of saturated fatty acids for the diabetic animals compared to that for the normal animals. The fat diet moderated the tendency towards saturation in the diabetic animals.

3. The fat diet had other effects on the diabetic animals; these included a reduced mortality rate, increased body-weight, a decrease in the daily water intake, and in the daily urinary excretion of glucose and urea.

4. In the diabetic animals the fat diet had no effect on the specific activities in the liver of hexokinase ( $E C$ 2.7.1.I), glucokinase ( $E C$ 2.7.1.2), phosphofructokinase (EC 2.7.I.II) and pyruvate kinase $(E C 2 \cdot 7 \cdot 1 \cdot 40)$. However, the specific activity of glucose-6-phosphatase $(E C 3.1 .3 .9)$ was reduced, while that of malate dehydrogenase (decarboxylating) (NADP) $\left(E C\right.$ I.I.I.40) was increased. The $\mathrm{NAD}^{+}: \mathrm{NADH}$ ratio, as calculated from liver pyruvate and lactate concentrations, tended to increase.

5. The results suggested that the fat diet moderated the long-term metabolic effects of diabetes.
\end{abstract}

In the diabetic animal there is an accumulation of the polyol, sorbitol, within the lens (van Heyningen, 1959) and it is now generally accepted that this increased polyol concentration is a causative agent in diabetic cataractogenesis. Similarly, in experimental galactosaemia, there is an accumulation of the corresponding polyol, dulcitol, in the lens resulting in cataract formation (Kinoshita, 1965a). The accumulation of high concentrations of polyol within the lens exerts osmotic stress on the tissue, resulting in changes in the metabolism of the lens leading ultimately to the formation of the cataract (Chylack \& Kinoshita, 1969). However, sorbitol accumulation is not limited to the lens in the diabetic animal; increased concentrations are found in other tissues, including peripheral nerve (Stewart, Sherman, Kurien, Moonsammy \& Wisgerhof, 1967) and retina (Hutton, Schofield, Williams \& Hollows, 1974). In the former instance it is postulated to be a causative agent in diabetic neuropathy. Thus central to the postulated role of sorbitol in both diabetic cataractogenesis and neuropathy is the concept that osmotic stress caused by the increased concentration of

* Present address: Department of Ophthalmology, Prince of Wales Hospital, Randwick, NSW 2031, Australia. 
sorbitol is a key factor in the development of the secondary biochemical and morphological changes.

However, diets rich in maize oil have been found to inhibit or delay the development of cataracts in the lens of diabetic rats (Patterson, 1955; Patterson, Patterson, Kinsey \& Reddy, I965) without greatly affecting the concentrations of sorbitol and polyol intermediates (glucose and fructose). That the sorbitol concentration remains high, and yet cataractogenesis is minimal or negligible, suggests that factors other than osmotic stress are important in the cataractogenic process. Hence the central issue is the mechanism by which a high-fat diet prevents cataract formation. Patterson et al. (1965) considered that the prevention of cataract formation may be prevention of an 'insult' to the lens, or it may involve some beneficial effect which overcomes the 'insult'. They concluded that the preventative action was associated with overcoming the effects of the 'insult'. However, there are no clear indications as to the mechanism by which this is achieved.

There are at least two general possibilities as to the mechanism by which the highfat diet may have a preventative action: (I) by modifying the metabolism of the animal as a whole in the diabetic state, or (2) by modifying diabetes-induced changes in the metabolism of the lens. This paper reports a re-evaluation of the effects of a highmaize-oil diet on cataractogenesis in the diabetic rat and a study of a number of possible mechanisms by which the diet may affect the cataractogenic process. In particular, the possible involvement of disturbances in the gross metabolism of the whole animal was studied, in addition to effects on the accumulation of polyol intermediates in both the lens and the retina, the latter being studied because it too is capable of accumulating the polyol.

\section{MATERIALS AND METHODS}

Diets. A high-maize-oil diet (fat diet) was prepared which was similar in nutrient composition to that used by Patterson et al. (1965). Dog meal (K9 Kennel Meal; Carnation Pty Ltd, Sydney, Australia) was pulverized and mixed with maize oil (Clifford Love \& Co., Sydney, Australia), and an aqueous solution (at $60^{\circ}$ ) of gelatin (Davis Gelatin Pty Ltd, Sydney, Australia). The mixture was allowed to set for $24 \mathrm{~h}$ at $0^{\circ}$, cut into small pieces (approximately $20 \mathrm{~mm}$ cubes) and stored at $-20^{\circ}$. The proportions of the ingredients in the diet $(\mathrm{g} / \mathrm{kg}$ dry weight) were: $670 \mathrm{dog}$ meal, 300 maize oil, 30 gelatin. The over-all nutrient composition $(\mathrm{g} / \mathrm{kg}$ dry weight) was: 200 crude protein (nitrogen $\times 6 \cdot 25$ ), 330 fat, 440 carbohydrate, 30 crude fibre; the diet received by control animals (standard diet) contained: 230 crude protein, 50 fat, 660 carbohydrate, 60 crude fibre. Although the protein content of both diets was the same, the fat diet contained a higher proportion of protein from animal sources than did the standard diet.

For the analysis of the fatty acid composition, samples of diets were dried in a vacuum desiccator over phosphorus pentoxide and then extracted by the method of Folch, Lees \& Sloane Stanley (1957) to obtain a total lipid extract. The fatty acid components in this extract were esterified using boron trifluoride in methanol ( $100 \mathrm{~g} / \mathrm{l})$ and analysed by gas-liquid chromatography as described later. 
Experimental procedures. The fat diet was fed ad lib. to male Norwegian hooded rats (Animal Breeding Unit, Prince Henry Hospital, Sydney, Australia) for periods of up to $285 \mathrm{~d}$ from when the animals were $50-100 \mathrm{~d}$ of age. Diabetes was induced in the animals with streptozotocin (1 I $\mathrm{mg} / \mathrm{kg}$ body-weight) (Hutton et al. 1974), 20-60 d before starting the dietary treatment. The animals had free access to water at all times. Diagnosis of diabetes was established $48 \mathrm{~h}$ after the streptozotocin injection by determination of the blood glucose concentration (Huggett \& Nixon, 1957), and by testing freshly voided urine samples from each animal for glucose (Labstix; Ames \& Co., Mulgrave, Victoria, Australia). Any streptozotocin-treated animal which at this time had a blood glucose concentration of less than $16.7 \mathrm{mmol} / 1$, or in which glucosuria was not present, was eliminated from the study. At the time of killing, animals with a blood glucose of less than $16 \cdot 7 \mathrm{mmol} / 1$ and with no evidence of glucosuria were also eliminated.

For the determination of urinary excretion of glucose and urea, animals were individually housed in metabolism cages and their urine was collected for a $24 \mathrm{~h}$ period (1 7.00-17.00 hours). During the collection periods the animals had free access to water, but food was withheld. The volume of urine which was passed by each animal was recorded, and samples were taken for the determination of glucose and urea.

Classification of diabetic cataracts. Forty-eight $\mathrm{h}$ before killing each animal the pupils of its eyes were dilated by the topical application of a solution of atropine ( $10 \mathrm{~g} / \mathrm{l})$, and the lenses were examined with a hand-held ophthalmoscope. The cataracts observed were classified as follows: grade $\mathrm{o}$, lens completely clear; grade $\mathrm{I}$, areas of abnormal refraction within the lens; grade 2 , small isolated areas of opacity within the lens; grade 3, widespread distribution of areas of opacity within the lens. Vascular features of the retina still visible; grade 4; widespread distribution of areas of opacity within the lens. Vascular features of the retina obscured. Cataract visible to the naked eye as a faint cloudiness in the lens; grade 5 , lens totally opaque. Cataract visible to the naked eye as a dense white mass.

Analytical procedures. Glucose in urine samples was determined by the glucoseoxidase method (Huggett \& Nixon, 1957), and urea by the method of Beale \& Croft (1961). The rates of excretion of glucose and urea were calculated from these determinations and corrected for the animal's body-weight.

The plasma concentrations of sodium and potassium ions, carbon dioxide, total protein, albumin, phosphate, cholesterol, urea- $\mathrm{N}$, uric acid and total bilirubin were determined using an Auto Analyzer (Model 12/60 SMA; Technicon Instruments Corporation, Tarry Town, New York, USA). Plasma glucose and free fatty acid (FFA) concentrations were determined by the methods of Huggett \& Nixon (1957) and Ho (1970) respectively. The plasma samples which were used for these determinations were pooled from groups of five animals.

The concentrations of free carbohydrates in the retina, lens and aqueous humour were determined by the method described by Hutton et al. (1974). This method is based on gas-liquid chromatographic analysis of the trimethylsilyl derivatives of the free carbohydrates. These determinations were made for animals which had been diabetic for $75 \mathrm{~d}$ or less, and only in those animals in which changes in the transparency 
of the lens were minimal (< grade 3 cataract). This restriction was imposed because the results of preliminary studies had suggested that marked changes occurred in the concentrations of glucose, sorbitol and fructose in lens and aqueous humour when cataracts developed to the nuclear stage ( $>$ grade 4 cataract).

For the determination of enzyme activities, livers were removed from diethyl etheranaesthetized rats and the main portion of each liver (approximately $4 \mathrm{~g}$ ) was immediately frozen in liquid $\mathrm{N}_{2}$. The remaining portion (approximately $\mathrm{I}$ g) was rinsed in ice-cold saline solution $(9 \mathrm{~g} \mathrm{NaCl} / 1)$, weighed, and then homogenized (Ultra Turrax homogenizer; Janke \& Kunkel KG, Staufen, West Germany) in 9 vol. of an ice-cold buffered salt solution (0.15 M-KCl, $0.05 \mathrm{M}-\mathrm{KHCO}_{3}, 0.006 \mathrm{M}-\mathrm{Na}_{2} \mathrm{EDTA}$ ), $\mathrm{pH} 7.4$. Samples of the homogenate were retained for the determination of protein (Lowry, Rosebrough, Farr \& Randall, 195I) and for the determination of glucose-6-phosphatase $(E C 3.1 .3 .9)$ activity by the method of Harper (1965). The remaining homogenate was subjected to ultracentrifugation ( $100000 \mathrm{~g}$ for $35 \mathrm{~min}$ ) and samples of the supernatant fraction were used for the determination of protein concentration and enzyme activities. Hexokinase $(E C$ 2.7.1.1) and glucokinase $(E C$ 2.7.1.2) were estimated by the method of Sharma, Manjeshwar \& Weinhouse (I963); fructose-r,6diphosphatase (EC 3.I.3.II), phosphofructokinase $(E C$ 2.7.I.II) and pyruvate kinase (EC 2.7.1.40) by the method of Shonk \& Boxer (1964); and malate dehydrogenase (decarboxylating) (NADP) (EC I.I.I.40) by the method of Hsu \& Lardy (1969). All determinations were done at $30^{\circ}$.

For the determination of the concentrations of pyruvate and lactate, the portion of each liver which had been frozen in liquid $\mathrm{N}_{2}$ was extracted with perchloric acid $(6 \circ \mathrm{ml} / \mathrm{l})$ by the method of Williamson, Lund \& Krebs ( 1967$)$. The concentrations of pyruvate and lactate were determined enzymically by the methods of Bucher, Czok, Lamprecht \& Latzko (1965) and Hohorst (1965) respectively. From these concentrations, values for $\mathrm{NAD}^{+}: \mathrm{NADH}$ in the cytoplasm were calculated by the method of Williamson et al. (1967).

For histological studies, tissues were removed from diethyl ether-anaesthetized animals, fixed for $24-48 \mathrm{~h}$ in a solution of formaldehyde ( $100 \mathrm{~g} / 1 \mathrm{lsaline})$. Tissue sections ( $5 \mu \mathrm{m}$ thickness) were stained with haemotoxylin and eosin, or haematoxylin and periodic acid-Schiff's reagent, and photographed using a Zeiss photomicroscope.

For the determination of the fatty acid composition of the standard diet and the fat diet, approximately I $g$ dry weight was taken. For the composition of epididymal adipose tissue, samples of approximately $200 \mathrm{mg}$ wet weight were taken from diethyl ether-anaesthetized rats. In each instance, the samples were homogenized in $25 \mathrm{ml}$ chloroform-methanol (2: I, v/v) using an all-glass Potter-Elvehjem homogenizer. The supernatant fluid fraction obtained after centrifugation of each homogenate $\left(275^{\circ} \mathrm{g}\right.$ for $5 \mathrm{~min}$ ) was treated by the method of Folch et al. (1957) to obtain a total lipid extract. The lipid extract was then dissolved in $5 \mathrm{ml} \mathrm{BF}_{3}$-methanol-benzene ( $\mathrm{I}: \mathrm{IO}: \mathrm{I}$, $(\mathrm{w} / \mathrm{v} / \mathrm{v})$ solution, and heated for $2 \mathrm{~h}$ at $100^{\circ}$ under dry $\mathrm{N}_{2}$ in a $10 \mathrm{ml}$ capacity screwcapped culture tube. Water $(5 \mathrm{ml})$ was then added to the solution which was extracted twice with $5 \mathrm{ml}$ light petroleum $\left(60-80^{\circ}\right)$. The light petroleum extracts were dried over anhydrous sodium sulphate and then passed through a $150 \mathrm{~mm} \times 10 \mathrm{~mm}$ column 
packed with Florisil (Sigma Chemical Co., St Louis, USA). The column bed was washed with $30 \mathrm{ml}$ light petroleum $\left(60-80^{\circ}\right)$, after which the fatty acid methyl esters bound to the column were eluted with diethyl ether $(3 \circ \mathrm{ml})$. The diethyl ether eluate was reduced to a volume of approximately $50 \mu \mathrm{l}$ using a stream of dry $\mathrm{N}_{2}$ at $30^{\circ}$ and then made up to a volume of $\mathrm{I}-\mathrm{IO} \mathrm{ml}$ with benzene. Samples $(\mathrm{I}-\mathrm{IO} / \mathrm{ll})$ of this solution were then taken for gas-liquid chromatographic analysis.

The efficiency of the above extraction procedures was determined from the recovery of radioactivity from $\left[\mathrm{U}_{-14}{ }^{14} \mathrm{C}\right]$ palmitic acid (specific radioactivity $900 \mathrm{mCi}$ / mmol; The Radiochemical Centre, Amersham, Bucks., UK) which was added at the first stage of the extraction procedure. Samples of the initial and final extracts were dissolved in a solution of $4 \mathrm{~g}$ PPO and $0.4 \mathrm{~g}$ POPOP $/ 1$ toluene and their radioactivity contents determined using a liquid-scintillation counter (Series 2000; Packard Instrument Co., Downers Grove, Illinois, USA). Quenching corrections were made using $\left[\mathrm{I}-{ }^{14} \mathrm{C}\right]$ hexadecane (specific radioactivity I $\cdot 07 \mu \mathrm{Ci} / \mathrm{g}$; The Radiochemical Centre) as an internal standard. From a series of four determinations with adipose-tissue extracts the recovery was $85.7 \pm 5.6 \%$.

Fatty acid methyl esters were analysed by gas-liquid chromatography using a Series 7300 gas-liquid chromatograph (Packard Instrument Co.) equipped with dual flameionization detectors. A $2 \mathrm{~m} \times 4 \mathrm{~mm}$ Pyrex glass column packed with Gas Chrom Q (100-120 mesh) coated with $150 \mathrm{~g}$ diethylene glycol succinate/kg was used for routine analyses. The operating conditions were as follows: injector and detector temperature $210^{\circ}$, column oven temperature $180^{\circ}$, carrier gas (helium) flow-rate $50 \mathrm{ml} / \mathrm{min}$, hydrogen flow-rate $20 \mathrm{ml} / \mathrm{min}$, air flow-rate $400 \mathrm{ml} / \mathrm{min}$.

The area of each peak in each chromatogram was calculated by triangulation and expressed as a percentage of the total peak area. The concentrations of the fatty acids in the diet and in adipose tissue samples were calculated by comparing the area of each peak in each chromatogram with that produced by the methyl ester of an internal standard (heptadecanoic acid) which had been added in a known amount at the first stage of the extraction procedure.

FFA and triglycerides in plasma samples were obtained by a modification of the method of McCarthy \& Duthie (1962). Freshly prepared plasma samples $(0.5 \mathrm{ml})$ were mixed with $2.5 \mathrm{ml}$ Dole's reagent (Dole \& Meinertz, 1960) for $30 \mathrm{~s}$ using a vortex mixer. Water $(2 \cdot 5 \mathrm{ml})$ was then added to the mixture which was extracted twice with $5 \mathrm{ml}$ heptane. The heptane extracts were reduced to approximately $100 \mu \mathrm{l}$ using a stream of dry $\mathrm{N}_{2}$ at $40^{\circ}$, made up to approximately $5 \mathrm{ml}$ with diethyl ether and then passed through a $100 \mathrm{~mm} \times 10 \mathrm{~mm}$ column of silicic acid. The column packing was prepared as originally described by McCarthy \& Duthie (1962). The column was washed with $25 \mathrm{ml}$ diethyl ether and the washings pooled with the original eluate and evaporated to dryness using a stream of dry $\mathrm{N}_{2}$ at $40^{\circ}$. The methyl esters of the fatty acid components of this fraction (triglyceride) were prepared, purified and analysed as described previously. The plasma FFA were eluted from the silicic acid column with $25 \mathrm{ml}$ formic acid-diethyl ether $(2: 100, \mathrm{v} / \mathrm{v})$. The eluate was evaporated using a stream of dry $\mathrm{N}_{2}$ at $40^{\circ}$, dissolved in $5 \mathrm{ml} \mathrm{BF}$-methanol ( $\left.\mathrm{r}: \mathrm{IO}, \mathrm{w} / \mathrm{v}\right)$, and then heated for $2 \mathrm{~min}$ at $100^{\circ}$ in a screw-capped culture tube under $\mathrm{N}_{2}$. The fatty acid methyl 
Table I. Fatty acid composition (mmol/mol total fatty acid) of the standard diet and the high-maize-oil diet (fat diet) given to non-diabetic and streptozotocin-induced diabetic male rats*

(Mean values for three determinations)

\begin{tabular}{|c|c|c|c|c|c|c|c|c|c|}
\hline \multirow[b]{2}{*}{ Diet† } & \multirow{2}{*}{$\begin{array}{l}\text { Total fatty acids } \\
\text { (g/kg dry wt) }\end{array}$} & \multicolumn{8}{|c|}{ Fatty acid } \\
\hline & & $\mathrm{C}_{14: 0}$ & $\mathrm{C}_{16: 0}$ & $\mathrm{C}_{16: 1}$ & $\mathrm{C}_{18: 0}$ & $\mathrm{C}_{18: 1}$ & $\mathrm{C}_{18: 2}$ & $\mathrm{C}_{18: 3}$ & $>\mathrm{C}_{18: 3}$ \\
\hline Standard & 50 & 53 & 217 & 33 & 98 & 286 & 242 & 18 & $5 \mathrm{I}$ \\
\hline Fat & 271 & I & I3I & 2 & 25 & 316 & 500 & 5 & - \\
\hline
\end{tabular}

esters in this solution were extracted, purified and analysed as described previously.

The concentration of triglyceride in the plasma was determined by the gas-liquid chromatographic method described previously, using [U-14 C]palmitate as an internal standard. The radioisotope (approximately roooo disintegrations/min) was added to the triglyceride fraction before esterification, and the radioactivity recovered in the final ester preparation was determined by liquid-scintillation counting. The fatty acid concentration in the final methyl ester preparation was determined by gas-liquid chromatography using authentic methyl stearate as a standard. From these values the concentration of triglyceride-fatty acids in the original plasma sample was calculated. The method was highly reproducible and gave values for the plasma triglyceride concentration which were in agreement with those determined by other methods.

\section{RESULTS}

The fatty acid compositions of the two diets are given in Table I. The fat diet contained a much higher content of total fatty acids, and a proportionately higher content of the polyunsaturated fatty acid, linoleic acid (18:2), than the standard diet.

The changes which occurred in the fatty acid composition of a total lipid extract from rat epididymal fat tissue with diet and diabetes are given in Table 2 . The animals used in this study had received a dosage of streptozotocin of only $90 \mathrm{mg} / \mathrm{kg}$ body-weight compared with the normal dose of $110 \mathrm{mg} / \mathrm{kg}$ body-weight. This lower dose was given so that the diabetic animals given the standard diet had epididymal fat of sufficient bulk to permit the sampling of at least $200 \mathrm{mg}$ wet weight of tissue for analysis.

The feeding of the fat diet to non-diabetic animals resulted in an increase of the relative amount of fatty acid $18: 2(P<0.0001)$ and a decrease in the relative amount of $16: 1(P<0.0001)$ in epididymal fat. These changes paralleled the differences in the fatty acid compositions of the two diets (Table $\mathrm{r}$ ) given to these groups of animals.

For animals given the standard diet, diabetes resulted in an increase in the relative amount of $18: 0(P<0.002)$ and a decrease in the relative amount of $18: 1(P<0.001)$ in epididymal fat. This situation was in contrast to that in animals given the fat diet; in the diabetic rats there was a small, non-significant decrease in the relative amount 
Table 2. Effect of the standard diet and the high-maize-oil diet (fat diet) on the fatty acid composition (mg/g total fatty acids) of adipose tissue of non-diabetic and streptozotocininduced diabetic male rats

(Mean values with their standard errors for duplicate determinations for three animals/treatment. Animals were killed at $180 \mathrm{~d}$ of age, having been given the experimental diets for $\mathrm{I} 30 \mathrm{~d}$ )

\begin{tabular}{|c|c|c|c|c|c|c|c|c|c|c|c|}
\hline \multirow[b]{3}{*}{ Treatment* } & \multirow[b]{3}{*}{ Diet $\uparrow$} & \multicolumn{10}{|c|}{ Main fatty acids } \\
\hline & & \multicolumn{2}{|c|}{$C_{16: 0}$} & \multicolumn{2}{|c|}{$C_{16: 1}$} & \multicolumn{2}{|c|}{$\mathrm{C}_{18: 0}$} & \multicolumn{2}{|c|}{$C_{18: 1}$} & \multicolumn{2}{|c|}{$\mathrm{C}_{18: 2}$} \\
\hline & & Mean & SE & Mean & SE & Mean & SE & Mean & SE & Mean & $\mathrm{SE}$ \\
\hline \multirow[t]{2}{*}{ Diabetic } & Standard & $49 I$ & 18 & 145 & 3 & 180 & I I & 85 & $\mathbf{I I}$ & 55 & 10 \\
\hline & Fat & $5 \mathrm{I} 8$ & 15 & I I & 5 & 72 & 9 & I 59 & 8 & 237 & 13 \\
\hline \multirow[t]{2}{*}{ Non-diabetic } & Standard & 538 & 18 & 125 & 4 & 95 & 8 & r99 & \multirow{2}{*}{$\begin{array}{l}7 \\
8\end{array}$} & 74 & 14 \\
\hline & Fat & 545 & 20 & 55 & 3 & 102 & 9 & I32 & & 136 & 11 \\
\hline
\end{tabular}

of $18: 0$, no change in that of $18: 1$, and a large increase in the relative amount of $18: 2$ $(P<0.001)$.

Although no significant variation in the total plasma concentrations of triglyceride and FFA were found among the four treatment groups in the present study, the fatty acid compositions of both these fractions were altered by diabetes and dietary treatment. The results of these analyses are given in Table 3 .

In the plasma FFA of both diabetic and non-diabetic groups of animals, feeding the fat diet resulted in a decrease in the relative amount $(P<0.01$ and $P<0.05$ respectively) and an increase in the relative amount of $18: 2(P<0.01)$. These changes paralleled the differences in the fatty acid compositions of the two diets (Table $I$ ) given to these animals.

Among the groups of animals given the standard diet, diabetes resulted in an increase in the relative amount of stearate $(P<0.05)$ and a small decrease in that of oleate $(P<0.02)$ in the plasma FFA. This situation was in contrast to that found in animals given the fat diet, in which diabetes did not significantly affect the relative amounts of $18: 0,18: 1$ and $18: 2$.

In the plasma triglyceride of non-diabetic and diabetic animals, compositional changes in most of the fatty acid components were apparent with the feeding of the fat diet. The most consistent of these changes were a decrease in the relative amount of 18:1 $(P<0.02)$, and an increase in that of $18: 2(P<0.02)$ and 20:4 $(P<0.02)$. The changes in the $18: 2$ composition of the plasma triglyceride reflected the differences in the $18: 2$ composition of the two diets (Table $\mathrm{I}$ ). The changes in plasma triglyceride20:4 composition may also have been related to differences in the $18: 2$ compositions of the two diets, since $18: 2$ in these diets was probably the principal precursor of 20:4 synthesis in these animals.

Among animals given the standard diet, diabetes resulted in an increase in the relative amount of $18: 0(P<0.001)$ and a large decrease in the that of $20: 4(P<0.02)$ in the plasma triglyceride-fatty acids; I8: I and I $8: 2$ were unaffected in these animals. 


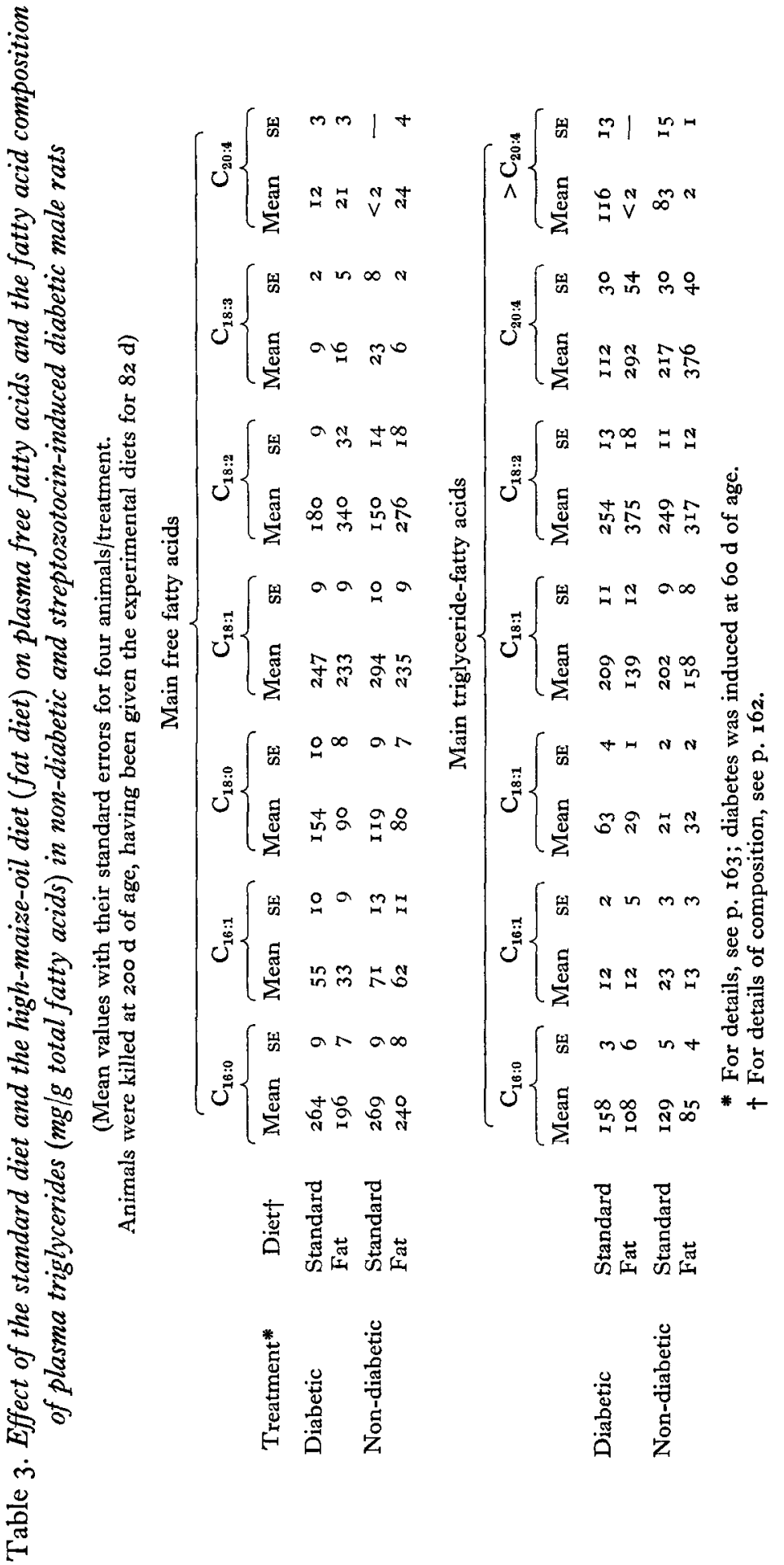


Table 4. Effect of the standard diet and the high-maize-oil diet (fat diet) on some gross anatomical and physiological changes in non-diabetic and streptozotocin-induced diabetic male rats

\begin{tabular}{|c|c|c|c|c|c|c|c|c|}
\hline \multirow{3}{*}{$\begin{array}{l}\text { Treatment*... } \\
\text { Diet } \nmid \quad \ldots\end{array}$} & \multicolumn{4}{|c|}{ Diabetic } & \multicolumn{4}{|c|}{ Non-diabetic } \\
\hline & \multicolumn{2}{|c|}{ Standard } & \multicolumn{2}{|c|}{ Fat } & \multicolumn{2}{|c|}{ Standard } & \multicolumn{2}{|c|}{ Fat } \\
\hline & Mean & SE & Mean & SE & Mean & $\mathrm{SE}$ & Mean & SE \\
\hline Body-wt (g) & 178 & I 5 & 201 & 14 & 3 I 7 & 26 & 321 & $3 \mathbf{I}$ \\
\hline Fat pad wt (g) & $<0 . I$ & - & $\mathrm{I} \cdot \mathbf{2}$ & 0.2 & $I \cdot 5$ & 0.3 & $2 \cdot 2$ & 0.2 \\
\hline Water intake $+(\mathrm{ml} / 24 \mathrm{~h})$ & 85 & I0 & 25 & 5 & 9 & 2 & 8 & 3 \\
\hline Glucose excretion (mg/24 h) & 928 & 176 & 156 & 80 & $<\mathrm{I}$ & - & $<\mathrm{I}$ & - \\
\hline Urea excretion (mg/24 h) & I3I & 16 & 83 & 14 & 85 & I 5 & 82 & I 5 \\
\hline
\end{tabular}

This situation was in contrast to that in animals given the fat diet in which the relative amount of $18: 2$ increased $(P<0.05)$, and there was a slight, non-significant decrease in that of $20: 4$ in the diabetic rats; triglyceride- $18: 0$ and $18: 1$ were not affected by diabetes in animals given the fat diet.

Animals which were maintained in an untreated chronic diabetic state on a standard diet were lethargic and showed signs of dehydration and wasting. In these animals the skin was thin and fragile, the abdomen was distended from an overfilling of the gut with food, the musculature was reduced in bulk, and the areas of fat deposits were markedly depleted. Within 2 weeks of feeding these animals the fat diet, there was a remarkable restoration of their general condition; so much so that apart from an overall smaller body size, they were indistinguishable from non-diabetic control animals. The extent to which the diet influenced the deposition of adipose tissue in diabetic animals is indicated by the changes which were found in the epididymal fat pad weight of these animals (Table 4 ).

The induction of diabetes resulted in a marked increase in the mass of the animals' adrenal tissue. The introduction of the fat diet partly reversed these changes, the adrenal weights of 'fat diet-diabetic' animals being intermediate between those of 'standard diet-diabetic' animals and those of non-diabetic animals given either diet. Histological examination of the adrenal glands of 180 -d-old male rats which had been subjected to the four different treatments (duration of diabetes $150 \mathrm{~d}$, dietary treatment period I $30 \mathrm{~d}$ ) suggested that the principal factor which was responsible for the increased adrenal mass in the diabetic rat was a proliferation of the cells of the zona fasiculata and the zona reticularis regions of the organ. The fat diet reduced the dimensions and vascularity of these areas of the adrenal gland in the diabetic rat.

The water intake of diabetic animals decreased $(P<0.00 \mathrm{I})$ after the introduction of the fat diet (Table 4 ). When these animals were transferred back to the standard diet 
Table 5. Effect of the standard diet and high-maize-oil diet (fat diet) on the incidence and severity of cataracts of the lens in non-diabetic and streptozotocin-induced diabetic male rats

(No. of eyes examined in parentheses. Animals were killed at $280 \mathrm{~d}$ of age, having been given the experimental diets for $108 \mathrm{~d}$ )

\begin{tabular}{|c|c|c|c|c|}
\hline \multirow[b]{2}{*}{ Treatment* } & \multirow[b]{2}{*}{ Diet $\uparrow$} & \multicolumn{3}{|c|}{ Incidence of cataract ( $\%$ eyes examined) } \\
\hline & & Gradef 0-I & Grade $f 2-3$ & Grade $f$ 4-5 \\
\hline Diabetic & $\begin{array}{l}\text { Standard (28) } \\
\text { Fat }(42)\end{array}$ & $\begin{array}{r}0 \\
20\end{array}$ & $\begin{array}{l}42 \\
75\end{array}$ & $\begin{array}{r}58 \\
8\end{array}$ \\
\hline Non-diabetic & $\begin{array}{l}\text { Standard (20) } \\
\text { Fat }(20)\end{array}$ & $\begin{array}{l}100 \\
100\end{array}$ & $\begin{array}{l}0 \\
0\end{array}$ & $\begin{array}{l}0 \\
0\end{array}$ \\
\hline
\end{tabular}

* For details, see p. 163 ; diabetes was induced at $\mathrm{x} 16 \mathrm{~d}$ of age.

+ For details of composition, see p. 162 .

† Cataracts were classified as follows: grade 0 , lens completely clear; grade $\mathrm{I}$, areas of abnormal refraction within the lens; grade 2 , small isolated areas of opacity within the lens; grade 3 , widespread distribution of areas of opacity within the lens. Vascular features of the retina still visible; grade 4, widespread distribution of areas of opacity within the lens. Vascular features of the retina obscured. Cataract visible to the naked eye as a faint cloudiness in the lens; grade 5 , lens totally opaque. Cataract visible to the naked eye as a dense white mass.

their water intake reverted to its pretreatment value. The rates of urinary excretion of glucose and urea in diabetic animals, determined over a $24 \mathrm{~h}$ fasting period, were markedly affected by the dietary regimen to which the animals had been subjected. ('Table 4). 'Standard diet-diabetic' animals excreted more glucose $(P<0.02)$ and more urea than 'fat diet-diabetic' animals. 'Fat diet-diabetic' animals excreted more glucose $(P<0.001)$, but approximately the same amount of urea, as groups of nondiabetic animals given either diet.

In diabetic rats given the standard diet, lens opacities which were visible to the naked eye (grade 4 or 5) appeared at 7 o or more $d$ after the induction of diabetes (mean time of onset $9 \circ \mathrm{d}$ ). Such cataracts were usually bilateral. There was no correlation between the times of appearance of mature cataracts in 'standard diet-diabetic' animals and their plasma glucose concentrations, although such a correlation has been found in alloxan-diabetic animals (Patterson, 1953).

The incidence and severity of ophthalmoscopic changes in groups of 'fat dietdiabetic' and 'standard diet-diabetic' animals which had survived $\mathrm{I} 64 \mathrm{~d}$ of severe diabetes (dietary treatment period $108 \mathrm{~d}$ ) is given in Table 5 . However, the tabulated values underestimated the true incidence of mature cataracts in these animals. During the period of the feeding trial the mortality rate among 'standard diet-diabetic' animals $(44 \%)$ was higher than that among 'fat diet-diabetic' animals ( $16 \%$ ). Moreover, the incidence of mature cataracts among the animals which died was higher in the 'standard diet-diabetic' group ( $80 \%$ of eyes examined) than in the 'fat dietdiabetic' group ( $13 \%$ of eyes examined). Of the original animals which were used for the feeding trial, approximately $70 \%$ of the 'standard diet-diabetic' animals and $6 \%$ of the 'fat diet-diabetic' animals developed mature cataracts during the ro $8 \mathrm{~d}$ period from the beginning of the dietary treatment. 
Table 6. Effect of the standard diet and the high-maize-oil diet (fat diet) on the concentrations ( $\mu \mathrm{mol} / \mathrm{g}$ protein) of free carbohydrates in the retina of non-diabetic and streptozotocin-induced diabetic male rats

(Mean values with their standard errors for eight determinations. Animals were killed at $140 \mathrm{~d}$ of age, having been given the experimental diets for $35 \mathrm{~d}$ )

\begin{tabular}{|c|c|c|c|c|c|c|c|c|c|}
\hline \multirow[t]{2}{*}{ Treatment* } & \multirow[t]{2}{*}{ Diet $t$} & \multicolumn{2}{|c|}{ Fructose } & \multicolumn{2}{|c|}{ Glucose } & \multicolumn{2}{|c|}{ Sorbitol } & \multicolumn{2}{|c|}{ myo-Inositol } \\
\hline & & Mean & $\mathrm{SE}$ & Mean & $\mathrm{SE}$ & Mean & SE & Mean & $\mathrm{SE}$ \\
\hline Diabetic & $\begin{array}{l}\text { Standard } \\
\text { Fat }\end{array}$ & $\begin{array}{l}2.4 \\
3.5\end{array}$ & $\begin{array}{l}0.4 \\
0.5\end{array}$ & $\begin{array}{l}17 \cdot 8 \\
12 \cdot 2\end{array}$ & $\begin{array}{l}4 \cdot 4 \\
2 \cdot 6\end{array}$ & $\begin{array}{l}2 \cdot 5 \\
2 \cdot 6\end{array}$ & $\begin{array}{l}0.3 \\
0.3\end{array}$ & $\begin{array}{r}10.5 \\
9.9\end{array}$ & $\begin{array}{l}0.8 \\
0.6\end{array}$ \\
\hline Non-diabetic & $\begin{array}{l}\text { Standard } \\
\text { Fat }\end{array}$ & $\begin{array}{l}<0.2 \\
<0.2\end{array}$ & - & $\begin{array}{l}I \cdot 8 \\
1 \cdot 0\end{array}$ & $\begin{array}{l}0.1 \\
0.2\end{array}$ & $\begin{array}{l}<0.3 \\
<0.3\end{array}$ & - & $\begin{array}{r}13.3 \\
9.7\end{array}$ & $\begin{array}{l}I \cdot 3 \\
0 \cdot 9\end{array}$ \\
\hline
\end{tabular}

Table 7. Effect of the standard and the high-maize-oil diet (fat diet) on the concentrations ( $\mu$ mollg protein) of free carbohydrates in the lens and aqueous humour of non-diabetic and streptozotocin-induced diabetic male rats

(Mean values with their standard errors for eight determinations.

Animals were killed at $140 \mathrm{~d}$ of age, having been given the experimental diets for $35 \mathrm{~d}$ )

\begin{tabular}{|c|c|c|c|c|c|c|c|c|c|}
\hline \multirow[t]{2}{*}{ Treatment* } & \multirow[t]{2}{*}{ Diet +} & \multicolumn{2}{|c|}{ Fructose } & \multicolumn{2}{|c|}{ Glucose } & \multicolumn{2}{|c|}{ Sorbitol } & \multicolumn{2}{|c|}{ myo-Inositol } \\
\hline & & \multicolumn{7}{|c|}{ (a) Lens } & $\mathrm{SE}$ \\
\hline Diabetic & $\begin{array}{l}\text { Standard } \\
\text { Fat }\end{array}$ & $\begin{array}{l}2 I \cdot 9 \\
24 \cdot 6\end{array}$ & $\begin{array}{l}2 \cdot 2 \\
3 \cdot 1\end{array}$ & $\begin{array}{l}9 \cdot 5 \\
8.4\end{array}$ & $\begin{array}{l}I \cdot I \\
I \cdot 6\end{array}$ & $\begin{array}{l}64 \cdot 7 \\
40 \cdot 0\end{array}$ & $\begin{array}{l}4 \cdot 0 \\
8 \cdot 1\end{array}$ & $\begin{array}{l}<0.1 \\
<0.1\end{array}$ & - \\
\hline Non-diabetic & $\begin{array}{l}\text { Standard } \\
\text { Fat }\end{array}$ & $\begin{array}{l}\mathrm{I} \cdot 9 \\
\mathrm{I} \cdot 9\end{array}$ & $\begin{array}{l}0.2 \\
0.2\end{array}$ & $\begin{array}{l}I \cdot 5 \\
0.8\end{array}$ & $\begin{array}{l}0.5 \\
0.2\end{array}$ & $\begin{array}{l}3 \cdot 2 \\
4 \cdot 2\end{array}$ & $\begin{array}{l}0.4 \\
0.4\end{array}$ & $\begin{array}{l}6 \cdot 3 \\
3 \cdot 7\end{array}$ & $\begin{array}{l}0.8 \\
0.4\end{array}$ \\
\hline \multicolumn{10}{|c|}{ (b) Aqueous humour } \\
\hline Diabetic & $\begin{array}{l}\text { Standard } \\
\text { Fat }\end{array}$ & $\begin{array}{r}22 \cdot 9 \\
8 \cdot 6\end{array}$ & $\begin{array}{l}4 \cdot 4 \\
2 \cdot 1\end{array}$ & $\begin{array}{l}5 \text { I I } \\
42 \text { I }\end{array}$ & $\begin{array}{l}24 \\
43\end{array}$ & $\begin{array}{r}10.1 \\
5.4\end{array}$ & $\begin{array}{l}2 \cdot 5 \\
2 \cdot 2\end{array}$ & $\begin{array}{l}<2.0 \\
<2.0\end{array}$ & - \\
\hline Non-diabetic & $\begin{array}{l}\text { Standard } \\
\text { Fat }\end{array}$ & $\begin{array}{l}2 \cdot 4 \\
2 \cdot 6\end{array}$ & $\begin{array}{l}0.6 \\
0.4\end{array}$ & $\begin{array}{l}\text { I } 89 \\
\text { r } 48\end{array}$ & $\begin{array}{l}13 \\
16\end{array}$ & $\begin{array}{l}<2.0 \\
<2.0\end{array}$ & - & $\begin{array}{l}<2.0 \\
<2.0\end{array}$ & - \\
\hline
\end{tabular}

The changes which were found in concentrations of free carbohydrates in the retina, and in the lens and aqueous humour of diabetic animals with dietary treatment are indicated in Tables 6 and 7 respectively. The mean blood glucose concentrations of 'standard diet-diabetic' animals and 'fat diet-diabetic' animals in these experiments were 20.9 and $18.6 \mathrm{mmol} / 1$ respectively.

The concentration of fructose, sorbitol, glucose and myo-inositol in the retinas of 'fat diet-diabetic' animals did not differ significantly from their concentrations in the retinas of 'standard diet-diabetic' animals (Table 6).

The concentration of sorbitol in the lens of 'fat diet-diabetic' animals was significantly lower than that in 'standard diet-diabetic' animals $(P<0.05)$ (Table 7$)$. The 
Table 8. Effect of the standard diet and high-maize-oil diet (fat diet) on the activities (IU/g protein) of some key enzymes in the liver of non-diabetic and streptozotocin-induced diabetic male rats

(Mean values with their standard errors for duplicate determinations for three or four animals/ treatment. Animals were killed at $150-180 \mathrm{~d}$ of age, having been given the experimental diets for $106 \mathrm{~d}$ )

\begin{tabular}{|c|c|c|c|c|c|c|c|c|}
\hline \multirow{3}{*}{$\begin{array}{ll}\text { Treatment } & \ldots \\
\text { Diet } & \ldots\end{array}$} & \multicolumn{4}{|c|}{ Diabetic } & \multicolumn{4}{|c|}{ Non-diabetic } \\
\hline & \multicolumn{2}{|c|}{ Standard } & \multicolumn{2}{|c|}{ Fat } & \multicolumn{2}{|c|}{ Standard } & \multicolumn{2}{|c|}{ Fat } \\
\hline & Mean & $\mathbf{S E}$ & Mean & SE & Mean & SE & Mean & SE \\
\hline Glucose-6-phosphatase $(E C 3 \cdot 1 \cdot 3 \cdot 9)$ & $7 \cdot 4$ & 0.4 & $5 \cdot 8$ & 0.3 & $4 \cdot 3$ & 0.6 & $3 \cdot 9$ & 0.5 \\
\hline Hexokinase $(E C 2 \cdot 7 \cdot \mathrm{r} .1)$ & $2 \cdot 2$ & 0.3 & I' 5 & 0.4 & $r \cdot 6$ & 0.3 & $I \cdot 9$ & 0.2 \\
\hline Glucokinase $(E C 2.7 \cdot 1.2)$ & $I \cdot 9$ & $\mathbf{0} \cdot \mathbf{I}$ & $2 \cdot 9$ & 0.4 & $12 \cdot 4$ & $2 \cdot 7$ & $8 \cdot 3$ & $I \cdot I$ \\
\hline Phosphofructokinase $(E C 2.7$. I.II $)$ & 4.2 & 0.7 & $4 \cdot 8$ & $\mathrm{I} \cdot 3$ & $8 \cdot 1$ & I.9 & II 4 & I.9 \\
\hline Pyruvate kinase $(E C 2.7,1.40)$ & 77 & 5 & 85 & II & 206 & $4 I$ & 148 & I 8 \\
\hline $\begin{array}{l}\text { Malate dehydrogenase (decarboxy- } \\
\text { lating) (NADP) (EC I. I I .40) }\end{array}$ & $2 \cdot 5$ & 0.9 & 8.0 & $I \cdot 2$ & $11 \cdot 0$ & 10 & $9 \cdot 8$ & 0.7 \\
\hline
\end{tabular}

concentrations of glucose and sorbitol in the aqueous humour did not differ significantly between these groups of diabetic animals.

The long-term diabetes had little effect on the concentrations of plasma constituents, with the exception of the increased plasma glucose concentration, regardless of the dietary status. In the four groups of animals under these conditions (age at killing 2 I2 d, duration of diabetes I $68 \mathrm{~d}$, dietary treatment period I I2 d), small increases were found in the diabetic animals in the plasma concentrations of cholesterol, FFA, urea and uric acid, but in each instance the concentrations were within the expected range of values for normal animals. No change was found in the plasma concentrations of $\mathrm{Na}^{+}, \mathrm{K}^{+}, \mathrm{CO}_{2}$, total protein, albumin, phosphate and bilirubin. Over all, none of the differences found were attributable to an effect of dietary treatment.

No significant differences were detected in tests for urinary ketones, blood, protein or $\mathrm{pH}$ (Labstix) between animals in any of the four treatment groups. The failure to detect aciduria or ketonuria in the diabetic animals indicated that severe ketoacidosis was not a feature of long-term diabetes in rats, even in those animals which consumed a diet potentially rich in ketogenic precursors (fat diet) The absence of ketoacidosis was consistent with the failure to find a marked increase in the plasma FFA concentration, or changes in the plasma $\mathrm{CO}_{2}$ concentration in diabetic animals.

The effect of the feeding the fat diet, and of diabetes on the activities of some key glycolytic and gluconeogenic enzymes, and the concentrations of pyruvate and lactate in rat liver are indicated in Tables 8 and 9.

Of the enzymes of the glycolytic pathway which were assayed, the activities of glucokinase $(P<0.001)$ and pyruvate kinase $(P<0.02)$ were reduced in diabetic animals given either diet. Dietary treatment did not significantly affect the activities of these enzymes in either the diabetic or non-diabetic rats. There was no significant 
Table 9. Effect of the standard diet and the high-maize-oil diet (fat diet) on the concentrations ( $\mu$ mol/kg wet weight) of pyruvate and lactate, and on cytoplasmic $N A D^{+}: N A D H$ in the liver of non-diabetic and streptozotocin-induced diabetic male rats

(Mean values with their standard errors for duplicate determinations for three or four animals/treatment. Animals were killed at $150-180 \mathrm{~d}$ of age, having been given the experimental diets for $106 \mathrm{~d}$ )

$\begin{array}{ll}\text { Treatment* } & \\ \text { Diet } \dagger & \ldots\end{array}$

\begin{tabular}{lcccc} 
Mean $_{\text {SE }}^{\text {Standard }}$ & \multicolumn{2}{c}{ Fat } \\
Pean & SE \\
Pyruvate & $4 \cdot 5$ & 0.9 & $5 \cdot 8$ & $1 \cdot 2$ \\
Lactate & 74 & 7 & 81 & 5 \\
NAD ${ }^{+}$NADH & 545 & 94 & 645 & 60
\end{tabular}

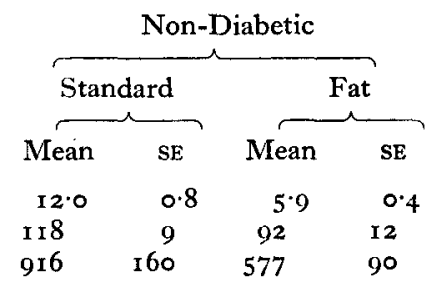

* For details, see p. I62; diabetes was induced at 30-60 d of age.

$\uparrow$ For details of composition, see p. 163 .

$\mp$ Calculated from the pyruvate and lactate concentrations by the method of Williamson, Lund \& Krebs (1967).

variation in activities of hexokinase and phosphofructokinase between the four treatment groups.

The activities of gluconeogenic enzymes was affected by both diet and diabetes. The activity of glucose-6-phosphatase was markedly increased in both groups of diabetic animals, but to a lesser extent in the animals given the fat diet $(P<0.02)$ than in animals given the standard diet $(P<0.002)$. The activity of a key lipogenic enzyme (malate dehydrogenase (decarboxylating) (NADP)) was reduced in the diabetic state only in animals given the standard diet $(P<0.001)$. No significant differences in the activity of this enzyme were found between non-diabetic animals given different diets. We have subsequently found no significant changes in the activities of two other key NADPH-generating enzymes under the same conditions; the activities of both hepatic glucose-6-phosphate dehydrogenase (EC I.I.I.49) and phosphogluconate dehydrogenase (decarboxylating) (EC I.I.I.44) were not significantly reduced (Hutton, Schofield, Williams, Regtop \& Hollows, unpublished results). It thus appears that, under these particular conditions, the activities of key NADPH-generating enzymes are not significantly reduced, although we have found the activity of a key lipogenic enzyme, ATP citrate lyase $(E C 4.1 .3 .8)$ was significantly reduced (Hutton, Schofield, Williams, Regtop \& Hollows, unpublished results).

The cytoplasmic $\mathrm{NAD}^{+}: \mathrm{NADH}$ ratio in liver tended to be decreased in the diabetic state only among animals given the standard diet. $\mathrm{NAD}^{+}: \mathrm{NADH}$ values for ' fat dietnon-diabetic' and 'standard diet-non-diabetic' animals were in agreement with reported values. The corresponding value for 'standard diet-diabetic' animals, however, was higher than that reported for acutely diabetic animals by Gumaa, McLean \& Greenbaum (197I).

\section{DISCUSSION}

The fatty acid profiles of the tissue and plasma fractions may be broadly summarized as follows. 
(I) 'Fat diet-non-diabetic' rats. The fatty acid profiles reflected the profile of the diet, e.g. an increase in the relative proportion of fatty acid $18: 2$. It is thus clear that, under the experimental conditions used in this study, the fat deposits of the body and the circulating plasma lipid fractions are representative of the dietary fat intake, particularly with respect to the increased relative proportion of unsaturated acids in the fat diet.

(2) 'Standard diet-diabetic' rats. There was a general trend towards a greater relative proportion of saturated acids, when compared to normal animals. In adipose tissue the relative proportion of $18: 0$ increased from 95 to $180 \mathrm{mg} / \mathrm{g}$ total fatty acids, while that of $18:$ I decreased from 199 to $85 \mathrm{mg} / \mathrm{g}$ total fatty acids. These changes confirm the findings of Benjamin \& Gellhorn (1964) that diabetes causes an impairment of desaturation mechanisms in adipose tissue.

(3) 'Fat diet-diabetic' rats. This group had, in general, a fatty acid profile which is intermediate between that of the 'standard diet-diabetic' and 'fat diet-non-diabetic' animals, as the profile may be expected to reflect the effect of two contradictory mechanisms, i.e. an increase in unsaturated fatty acids derived from the fat diet, and a decrease in unsaturated fatty acids associated with the defect in the desaturation mechanisms in the diabetic state. Hence, it was not resolved as to whether the ability of the fat diet to moderate the changes in the fatty acid composition in diabetic tissues was related entirely to the capacity of the dietary lipid to alter the fatty acid composition, or whether it was related to the action of the diet to reduce the severity of metabolic changes induced by the diabetic state. However, irrespective of these mechanisms, it is unlikely that, in the diabetic condition, the fat diet with its concomitant increase in circulating unsaturated acids acts directly upon the lens since it was found that the aqueous humour contained no measurable concentrations of lipid.

The present results confirmed that a diet rich in maize oil prevented the development of mature cataracts in the lenses of diabetic rats, but did not substantially alter the capacity of the tissue to accumulate sorbitol-pathway intermediates (Patterson et al. 1965). The diet used in the present studies, however, was not as successful as that used by Patterson $e t$ al. (1965), since a number of 'fat diet-diabetic' animals still developed mature cataracts and there was a high incidence of opacities of an intermediate grade in many treated animals. However, it should be noted that the index of cataractogenesis used by Patterson et al. (1965) was 'the appearance of a white opacity' visible to the naked eye, i.e. a mature cataract.

The differences which were found in the concentration of sorbitol in the lens between 'standard diet-diabetic' animals and 'fat diet-diabetic' animals did not appear to account for the action of the diet to prevent diabetic cataract. Among diabetic rats given the standard diet, the variation in the sorbitol concentrations between the two lenses of the same diabetic animal was as large as the variation between the lenses of different diabetic animals. If the sorbitol concentration was the only important factor in cataractogenesis, then this situation would suggest that the variation in the incidence of cataracts between the two lenses of the same diabetic animal would be the same as the variation in their incidence between different diabetic animals. However, this was not the situation. 
The differences which were found in the values for sorbitol:fructose and sorbitol: glucose ratios in the lens between diabetic animals given the different diets suggested that possibly the $\mathrm{NAD}^{+}: \mathrm{NADH}$ and $\mathrm{NADP}^{+}: \mathrm{NADPH}$ ratios in the lens of diabetic rats may have been affected by the fat diet. The levels of the pyridine nucleotides in the lens, and their oxidized:reduced ratios may be important in the regulation of sorbitol metabolism in the lens (Kinoshita, Futterman, Satoh \& Merola, 1963; Kuck, 1966). Whether the converse is true, and whether there is any relationship between the changes found and the action of the fat diet to prevent diabetic cataract cannot presently be predicted.

The finding that the concentration of the free carbohydrates in the aqueous humour of diabetic animals did not vary greatly with the dietary treatment, apparently excluded the possibility that the fat diet acted to prevent diabetic cataract by altering the osmotic gradient due to free carbohydrates between the lens and aqueous humour. Determinations of the concentrations of free carbohydrates in the aqueous humour were, however, made after a $4 \mathrm{~h}$ fast, and the possible importance of postprandial variation in the carbohydrate concentrations in the aqueous humour was not assessed. In this respect it may be relevant that a diet of avocado oil and casein has been found to enhance the increase in the blood glucose concentration in juvenile diabetic patients after the ingestion of a standard glucose load (Estrich, Ravnik, Schlierf, Fukayama \& Kinsell, 1967).

The results of the study of enzyme activities suggested that in the liver of the diabetic animals given either diet glycolysis was decreased, gluconeogenesis was increased and lipogenesis was decreased. The fat diet apparently moderated the change in gluconeogenesis and lipogenesis in the diabetic state.

The results of determinations of liver metabolites were consistent with these conclusions. The discrepancy between the reported values for $\mathrm{NAD}^{+}: \mathrm{NADH}$ for acutely diabetic animals and the values obtained here emphasize the need for caution in the interpretation of these results. The theoretical framework in which such results may be interpreted has basically been established for physiological disturbances of relatively short duration only (Gumaa et al. 1971) and not for long-term studies such as those undertaken in the present work.

The urinary glucose and urea excretion results suggested that, under conditions of fasting of short duration, the rate of gluconeogenesis from endogeneous protein was lower in 'fat diet-diabetic' animals than in 'standard diet-diabetic' animals.

The total impression gained from the excretion studies, from the study of some liver enzymes, and from the physical conditions of the animals, was that the feeding of the fat diet to diabetic animals resulted in the establishment of a new steady-state of energy metabolism, which is possibly characterized by a decreased turnover of body glucose accompanied by decreased gluconeogenesis in the liver and increased deposition of adipose tissue reserves. A key to the mechanisms by which this new state of energy metabolism was controlled was suggested by the histological differences in the adrenals of 'standard diet-diabetic' and 'fat diet-diabetic' animals. The histological evidence suggested that the mean diurnal plasma concentration of glucocorticoid may be higher in diabetic animals given the standard diet than in diabetic animals given the 
fat diet. The implication that glucocorticoid secretion is increased in diabetes is supported by the finding that the plasma levels of corticosterone in rats increases after the induction of diabetes with alloxan (Fechner \& L'Age, I972). Hence for animals given the fat diet, the severity of the disturbance in energy metabolism may be reduced as a consequence of the decrease in the mass of glucocorticoid secreting tissue in the diabetic animals.

Interpretation of the action of the diet in terms of the possible provision of an alternative energy substrate to the lens (Patterson, Patterson, \& Bunting, I962) was not supported by the results. Of the alternative energy sources which may have been provided by the change in diet, or which may have been available to the lens as a consequence of the altered endocrinological status of the animal, most are required to be oxidatively metabolized. However, the body of the lens, with the possible exception of the anterior epithelium, has a limited capacity for the utilization of oxygen. It is likely, in fact, that the lens can obtain sufficient energy from glycolysis (Kinoshita, I965 $b$; van Heyningen, 1965 ).

It should perhaps be noted that the diabetic animals used in these studies were longterm diabetic animals; in many instances they had been diabetic for more than roo $\mathrm{d}$ after the induction of a diabetic state with streptozotocin. It appears that, under these conditions, they have established a new, albeit fragile, metabolic steady-state which is characterized by the absence of ketonaemia and its related complications. This is in direct contrast to the state of diabetic animals in the first few days after chemical induction of diabetes; in this instance, the animals show the classic symptoms of acute diabetes, including ketoacidotic complications. Diabetic animals who survive this initial acute phase subsequently do not show these symptoms under normal conditions in the long term. Mansford \& Opie (I968) have similarly found that streptozotocininduced diabetic rats are neither ketonaemic, nor do they have significantly increased plasma FFA concentrations. Since the long-term diabetic animals are completely devoid of body fat, and hence ketogenic precursors, it is not surprising that ketoacidosis etc. is absent. It is thus clear that caution must be exercised in directly equating the status of chemically induced diabetes in experimental animals to human diabetes; for example, retinopathy is frequently found in human diabetics, whereas all attempts to exactly reproduce these morphological changes in diabetic rats have been unsuccessful.

In summary, the feeding of a diet rich in maize oil to diabetic rats had a multiplicity of actions upon the physiological status of the animals, ranging from specific effects to non-specific effects such as the influence on the state of body hydration. The results emphasize the diversity of mechanisms involved in the process of cataractogenesis, and the significance of the metabolic status of the whole animal with respect to metabolic changes at a localized site such as the lens.

P.J.S., J.F.W and F.C.H. gratefully acknowledge the support of the National Health and Medical Research Council of Australia, and J.C.H. gratefully acknowledges the support of a Commonwealth Postgraduate Award. We thank Upjohn and Co., Sydney, Australia, for the gift of streptozotocin. 


\section{REFERENCES}

Beale, R. N. \& Croft, D. (1961). F. clin. Pathol. 14, 418.

Benjamin, W. \& Gellhorn, A. (1964). F. biol. Chem. 239, 64.

Bucher, T., Czok, R., Lamprecht, W. \& Latzko, E. (1965). In Methods of Enzymatic Analysis, p. 253

[H. U. Bergmeyer, editor]. New York: Academic Press.

Chylack, L. T. \& Kinoshita, J. H. (1969). Invest. Ophthal. 8, 4or.

Dole, V. P. \& Meinertz, H. (1960). F. biol. Chem. 235, 2595.

Estrich, D., Ravnik, A., Schlierf, G., Fukayama, G. \& Kinsell, L. (1967). Diabetes 16, 232.

Fechner, W. \& L'Age, M. (1972). Acta endocr. Copenh. 159, Suppl., 89.

Folch, J., Lees, M. \& Sloane Stanley, G. H. (1957). F. biol. Chem. 226, 497.

Gumaa, K. A., McLean, P. \& Greenbaum, A. L. (1971). In Essays in Biochemistry, vol. 7, p. 39 [P. N. Campbell and F. Dickens, editors]. London: Academic Press.

Harper, A. E. (I965). In Methods of Enzymatic Analysis, p. 788 [H. U. Bergmeyer, editor]. New York: Academic Press.

Ho, R. J. (1970). Analyt. Biochem. 36, 105.

Hohorst, H. J. (1965). In Methods of Enzymatic Analysis, p. 266 [H. U. Bergmeyer, editor]. New York: Academic Press.

Hsu, R. Y. \& Lardy, H. A. (1969). Meth. Enzym. 13, 230.

Huggett, A. St G. \& Nixon, D. A. (1957). Biochem. Э. 66, $12 P$.

Hutton, J. C., Schofield, P. J., Williams, J. F. \& Hollows, F. C. (r974). Aust. J. exp. Biol. med. Sci. 52, 361 .

Kinoshita, J. H. (1965a). Invest. Ophthal. 4, 786.

Kinoshita, J. H. (1965b). Invest. Ophthal. 4, 6r9.

Kinoshita, J. H., Futterman, S., Satoh, K. \& Merola, L. O. (1963). Biochim. biophys. Acta 74, 340.

Kuck, J. F. R. (1966). Invest. Ophthal. 5, 65.

Lowry, O. H., Rosebrough, N. J., Farr, A. L. \& Randall, R. J. (195I). F. biol. Chem. 193, 265.

McCarthy, R. D. \& Duthie, A. H. (1962). Lipid Res. 3, I I 7 .

Mansford, K. R. L. \& Opie, L. (I968). Lancet i, 670.

Patterson, J. W. (1953). A. F. Physiol. r72, 77.

Patterson, J. W. (1955). Proc. Soc. exp. Biol. Med. 90, 706.

Patterson, J. W., Patterson, M. E. \& Bunting, K. W. (I962), Exp. Eye Res. I, 4 I r.

Patterson, J. W., Patterson, M. E., Kinsey, E. V. \& Reddy, D. V. N. (1965). Invest. Ophthal. 4, 98.

Sharma, C., Manjeshwar, R. \& Weinhouse, S. (I963). F. biol. Chem. 238, 3840.

Shonk, C. E. \& Boxer, G. E. (1964). Cancer Res. 24, 709.

Stewart, M. A., Sherman, W. R., Kurien, M. M., Moonsammy, G. I. \& Wisgerhof, M. (1967).

7. Neurochem. 14, 1057 .

van Heyningen, R. (1959). Nature, Lond. 184, I94.

van Heyningen, R. (1965). Biochem. Y. 96, 419.

Williamson, D. H., Lund, P. \& Krebs, H. A. (1967). Biochem. F. ז03, 514. 